Corresponding Author: Abbakar Adam Mohammed; email:

abbakarad67@yahoo.com

Received 21 February 2019

Accepted 12 May 2019

Published 30 September 2019

Production and Hosting by

Knowledge E

(c) Abdalla Hassan Mudardum and Abbakar Adam

Mohammed. This article is distributed under the terms of the Creative Commons

Attribution License, which permits unrestricted use and redistribution provided that the original author and source are credited.

Editor-in-Chief:

Prof. Mohammad A. M. Ibnouf

\section{Prevalence and Risk Factors for Hepatitis B Infection among Pregnant Women attending Antenatal Clinic in UM Dafog Area, South Darfur State, Sudan}

\section{Abdalla Hassan Mudardum¹ and Abbakar Adam Mohammed²}

${ }^{1}$ Health officer, Ministry of Heath, South Darfur State, Sudan/ZOA International, Nyala Office

${ }^{2}$ Epidemiology and Public Health, Department of Preventive Medicine \& Public Health, Faculty of Veterinary Science, University of Nyala

\section{Abstract}

Background: Sudan is an endemic country for hepatitis B virus (HBV). Screening for HBV during pregnancy may help in instituting interventions to minimize vertical transmission. HBV in pregnant women in remote areas of Darfur were uncovered by the previous studies in Sudan, Objectives: This study was aimed to determine the seroprevalence of HBV and the possible risk factors for its acquisition among antenatal care attendants in Um Dafog area, South Darfur State, Sudan.

Methods: A cross-sectional study was conducted between July 2018 and January 2019 in Um Dafog area. Blood samples were collected from 165 (143 from Sudan and 22 from Central African Republic) pregnant women attending the Antenatal Um Dafog Clinic. Serum was separated and tested for HBV marker using rapid HBsAg test. Information on socio-demographic and other pertinent data was collected using a structured questionnaire. Informed consent was obtained and confidentiality of personal data was assured.

Results: HBsAg was detected in $8.5 \%$ of study population. Participants from Central African Republic recorded higher prevalence (18.2\%) than those from Sudan (7\%). However, there was no significant association $(p>0.05)$ between prevalence of $\mathrm{HBsAg}$ and residence, history of blood transfusion, tattooing, circumcision, surgical procedure, cupping therapy, caesarean section, ear piercing, unsafe injection, and jaundice or liver problems.

Conclusion: The study concluded that the prevalence of HBV among pregnant women in Um Dafog area is of high endemicity according to the WHO, hence the need for established public health interventions that lead to reduction of HBV transmission.

Keywords: hepatitis B, pregnant women, Um Dafog, Sudan 


\section{Introduction}

Hepatitis B virus (HBV) infection is a serious public health problem worldwide. It is caused by the HBV that infects the liver and causes hepatocellular necrosis, carcinoma, and inflammation [1]. Many of the carriers do not realize that they are infected with the virus rendering the HBV to be known as a silent killer [1].The main modes of horizontal transmission of HBV are unprotected sexual contact with an infected individual, inadvertent percutaneous or mucosal contact with blood or infectious body fluids among people in close daily contact (household members) through ear piercing, cupping therapy, or sharing needles and syringes among injecting drug users, or from an infected mother to her baby at birth [2, 3]. HBV poses a risk to healthcare workers who sustain accidental needle stick injuries while caring for HBV-infected people [4]. Uncommon vertical transmission is generally associated with antepartum hemorrhage and placental tears [4], and it depends on the time at which a pregnant woman acquired the HBV infection [5]. Unsafe blood transfusion, female circumcision, surgical and dental procedures, intravenous drug abuse, and some socio-demographic factors are the common risk factors but vary globally depending on religious and cultural backgrounds of the communities [6].

Worldwide, hepatitis B surface antigen (HBsAg) seroprevalence varies markedly by geographical region, with the highest prevalence (> 5\%) in sub-Saharan Africa, East Asia, some parts of the Balkan regions, the Pacific Islands, and the Amazon Basin of South America, while prevalence below $2 \%$ is in Central Latin America, North America, and Western Europe [1]. The prevalence of HBV among pregnant women referring to prenatal healthcare or admitted for birth in some African countries was found to be $3.2 \%$ in Eritrea [7], 6.9\% in Ethiopia [8], 11.8\% in northern Uganda [9], 10.6\% in Central African Republic [10], 11\% in South Sudan[11], and 9.0\% in Nigeria [12].

Studies on prevalence and risk factors associated with HBV acquisition among pregnant women attending antenatal care clinics in different parts of the Sudan revealed a prevalence of $7.5 \%$ among pregnant Sudanese women attending antenatal clinic at the Khartoum Teaching Hospital [13], 6.8\% in central Sudan [14], 5.6\% in the Omdurman Maternity Hospital [15], 5.1\% in the Wad Medani Maternity Hospital [16], and 18\% in Al Fashir town [17]. On other cross-sectional studies conducted in Nyala, a prevalence of $6.25 \%$ was reported among blood donors [18]. Antenatal screening for HBsAg to all pregnant women and treating those HBV-infected before delivery and vaccination of their babies at birth has been recommended widely to prevent transmission around birth, yet it is not a routine practice in most health settings of Sudan [1]. 
Information on the situation of the disease in remote marginalized areas of the Sudan with limited healthcare facilities is scarce, therefore this study is focused to determine the seroprevalence and to evaluate the risk factors associated with hepatitis B infection among pregnant women attending the Antenatal Care Clinic (ANC) in the Um Dafog area, South Darfur State.

\section{Methods}

\subsection{Study area}

The study was carried out in the Um Dafog area, South Darfur State, at the Um Dafog clinic which is the only health facility including the reproductive health service. It serves around 400 pregnant women visiting the ANC annually. The reproductive health service is operated by the Rufida Health Foundation(RHF), a non-governmental organization.

Um Dafog town (approximately $350 \mathrm{~km}$ far from Nyala, the capital of South Darfur State) is the headquarter of the Um Dafog locality, which is located in the southern west of South Darfur State, sharing the border with Central African Republic (Figure 1). The estimated number of population of the town is around 30,000. The livelihood activities include cash crop farming, pastoral farming, fishing, border trade, and seasonal labor.

\subsection{Study design and data collection}

The study was a descriptive cross-sectional study conducted for six months period extending from July 2018 to January 2019. The study population consisted of all pregnant women attending the ANC for routine check-up and those that matched the inclusion criteria (confirmed pregnancy, had not been vaccinated against hepatitis $B$, and did not know their hepatitis B status) during the study period. All pregnant women who were vaccinated against HBV or had previously tested positive for any hepatitis $B$ sero-markers were excluded. Pregnant mothers who attended the clinic for more than one visit during the study period were excluded for subsequent visits using a unique mark on their cards.

Finger stick whole blood drop was aseptically collected by using sterile lancet and sample dispensing plastic dropper, and serum was separated and tested for HBsAg using rapid HBV surface antigen test (Advanced Quality One Step HBsAg Test); the result was red according to the manufacturer's instructions (ITH Biotech Company, 2016). 
Information on socio-demographic and other pertinent data were collected using a structured questionnaire that was adapted from the standard WHO protocol for the assessment of hepatitis B infection in antenatal patients.

\subsection{Ethics approval and consent to participate}

The study was approved by the Research Directorate, Ministry of Health, South Darfur State (Ref. 1/b/50:N) and informed consent was obtained from all participants before the collection of samples and data.

\subsection{Data processing and analysis}

The data was processed and analyzed by using Statistical Package for Social Sciences (SPSS) version 21. Chi-square and Fisher Exact test were used to test if there is significant association between the occurrence of HBV and different variables at 95\% confidence level. Odds ratio (OR) with their 95\% confidence intervals $(\mathrm{Cl})$ was calculated to estimate the magnitude of the association between HBsAg positivity and the study variables as possible risk factors; $p<0.05$ was considered significant.

\section{Results}

A total of 165 eligible study participants were recruited into the study with their consent, 143 (87\%) were from Sudan and 22 (13\%) from Central African Republic. Of the 165 subjects, 14 (8.5\%) were tested positive for hepatitis B infection using advanced quality HBsAg rapid test (Figure 2).

Most of the pregnant women enrolled in the study were in the age group 20$30 \mathrm{yr}$ (57.6\%). The youngest age noted during the study period was $15 \mathrm{yr}$, while the oldest being $40 \mathrm{yr}$ (86\%), with mean age \pm SD of $27.64 \pm 4.53$. The distribution of HBsAg positive pregnant women according to their socio-demographic characteristics including age, residence, marital status, occupation, and level of education is shown in Table 1.

Different potential risk factors for hepatitis B infection including the history of blood transfusion, surgical procedure, dental procedure, tattooing/traditional mark, cupping therapy, unsafe injection, caesarean section, ear piercing, jaundice, jaundice among husbands of participants, and female genital circumcision were assessed. The Statistical 


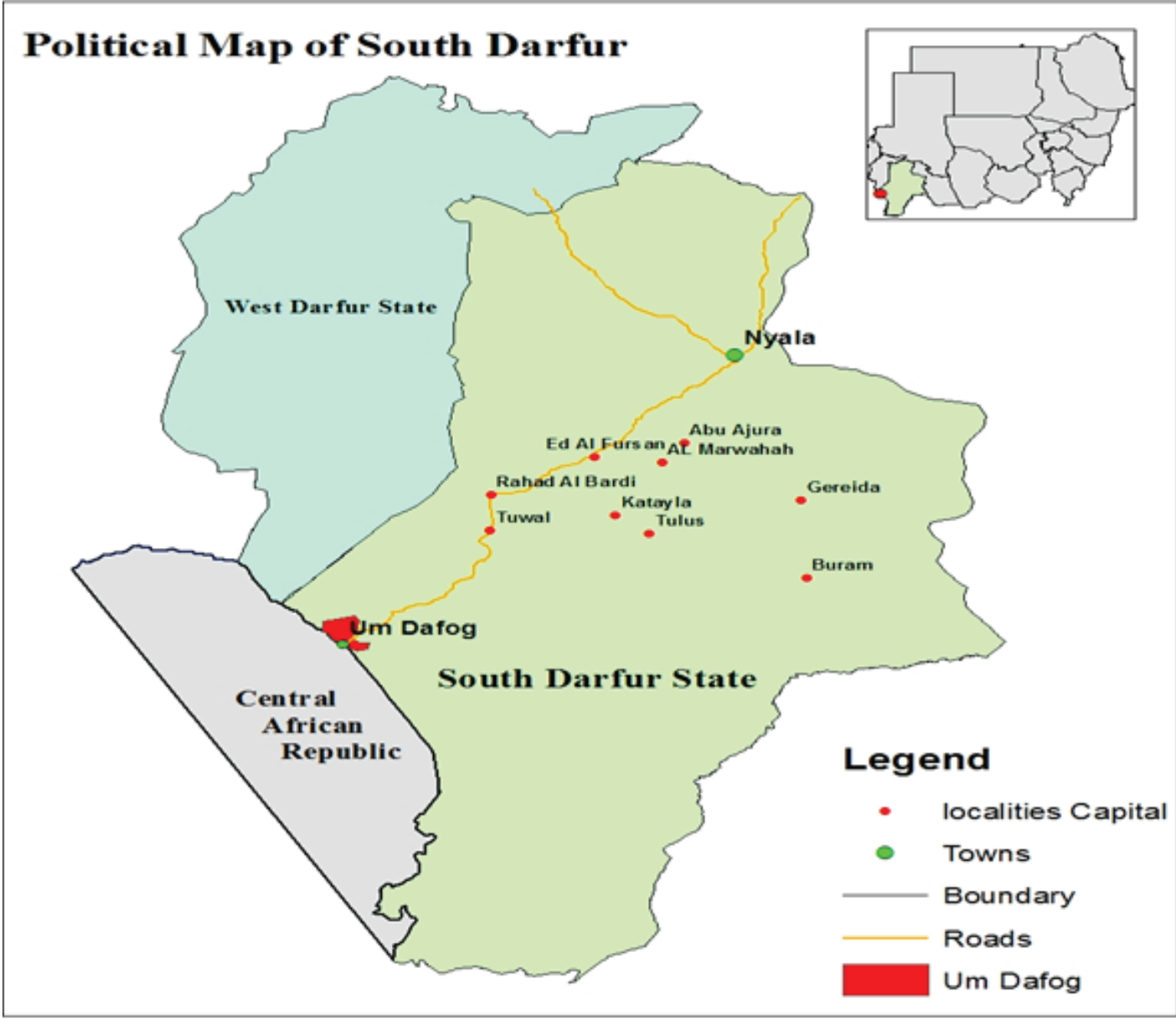

Figure 1: A map of south Darfur State showing the study area.

analysis of data revealed no significant association $(p>0.05)$ between the prevalence rate of HBsAg and studied potential risk factors (Table 2).

\section{Discussion}

This descriptive cross-sectional hospital-based study was carried out at the Um Dafog clinic, South Darfur State to determine the prevalence and evaluate the risk factors of hepatitis B viral infection among pregnant women attending the ANC.

The present findings were believed to be the first data of HBV seroprevalence among pregnant women in South Darfur State. The overall prevalence rate of hepatitis among pregnant women in the Um Dafog area was found to be $8.5 \%$, which is higher than the WHO cut-off level of endemicity (8\%), hence classifying the area as highly endemic. This result is close similar to $8.2 \%$ in the Central African Republic that was reported by 


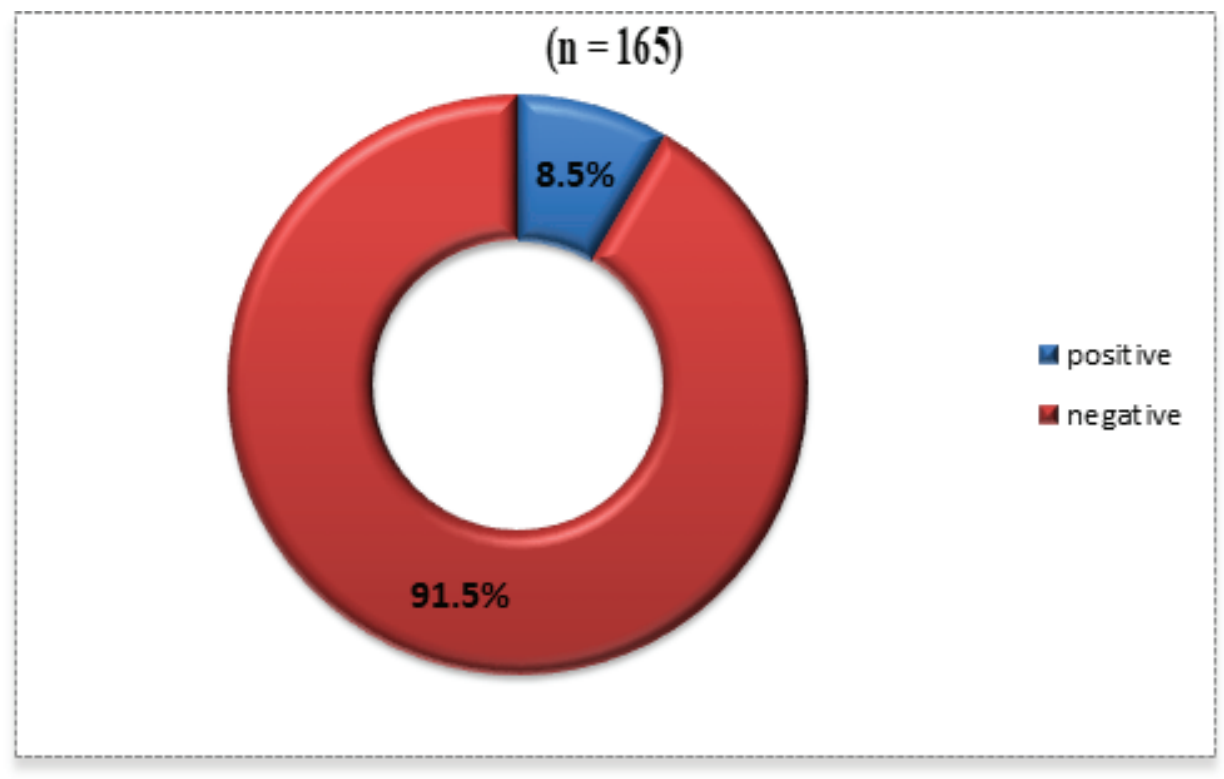

Figure 2: The test result of HBsAg among pregnant women attending Antenatal Care (ANC) Clinic at the Um Dafog area, South Darfur State, Sudan during July 2018 to January 2019.

Komas et al. [19], but it is higher than $5.6 \%, 5.1 \%$, and $7.5 \%$ that reported by Elsheikh et al., Osman et al., and Abuelgasim $[13,15,16]$ at the Omdurman Maternity Hospital, central Sudan and Khartoum Teaching Hospital, respectively. However, it is much lower that the result of El Gasim et al. [17] who found 18\% positive cases for HBsAg among pregnant women attending antenatal clinics in Al Fashir, North Darfur State.

These variations in the prevalence rate may be due to the differences in efficiency of exposure and cultural backgrounds of the communities or to the sensitivity of different diagnostic tests used.

The age-specific prevalence of HBV showed that women $<20 \mathrm{yr}$ old were with the highest HBV prevalence (9.4\%), while the age group 31-40 yr was found free of HBV. The community under the study is semi-nomadic community, and usually young girls are married at a very tender age, this could explain why we have included this age group. This result is similar to that recorded by Bayo et al. [9] in Uganda who found the highest HBsAg positivity (20\%) in women aged $20 \mathrm{yr}$ or less, but in contrast with the result of Abioye et al. [12] who recorded the highest HBsAg positivity (15.78\%) for those aged $37-48 \mathrm{yr}$.

This could be due to community exposure to risk factors.

The prevalence rate among pregnant women residing in the Central African Republic was found to be higher (18.2\%) than among those from Sudan (7\%). This might be attributed to geographical variations and the cultural and behavioral differences regarding the exposure to possible risk factors of $\mathrm{HBV}$ infection. 
TABLE 1: Distribution of HBsAg-positive pregnant women according to their socio-demographic characteristics.

\begin{tabular}{|c|c|c|c|}
\hline \multirow[t]{2}{*}{ Characteristic } & \multirow[t]{2}{*}{ No. tested } & \multicolumn{2}{|c|}{ HBsAg +ve } \\
\hline & & Frequency & $\%$ \\
\hline \multicolumn{4}{|l|}{ Age/years } \\
\hline$>20$ & 64 & 6 & 9.4 \\
\hline $20-30$ & 95 & 8 & 8.4 \\
\hline $31-40$ & 6 & 0 & 0.0 \\
\hline \multicolumn{4}{|l|}{ Residence area } \\
\hline Sudan & 143 & 10 & 7.0 \\
\hline Central African Republic & 22 & 4 & 18.2 \\
\hline \multicolumn{4}{|l|}{ Marital status } \\
\hline Single & 6 & 1 & 16.7 \\
\hline Married & 158 & 13 & 8.2 \\
\hline Divorced & 1 & 0 & 0.0 \\
\hline \multicolumn{4}{|l|}{ Occupation } \\
\hline House wife & 107 & 10 & 9.3 \\
\hline Business & 2 & 0 & 0.0 \\
\hline Farmer & 55 & 4 & 7.3 \\
\hline Employee & 1 & 0 & 0.0 \\
\hline \multicolumn{4}{|l|}{ Educational level } \\
\hline Illiterate & 63 & 5 & $7.9 \%$ \\
\hline Khalwa (school of Holy Quran) & 27 & 3 & $11.1 \%$ \\
\hline Primary (Basic) school & 57 & 5 & $8.8 \%$ \\
\hline Secondary school & 17 & 1 & $5.9 \%$ \\
\hline University Graduate & 1 & 0 & $0.0 \%$ \\
\hline Total & 165 & 14 & 8.5 \\
\hline
\end{tabular}

Several potential risk factors for contracting HBsAg were evaluated including the history of blood transfusion, surgical and dental procedures, ear piercing, tattooing, cupping therapy, unsafe injection, caesarean section, female genital circumcision, liver problem or jaundice, husband's history of jaundice, and abortion or miscarriage. No significant association was observed between the studied risk factors and HBsAg. This agrees with the results of Elsheikh et al. [15] in Omdurman, however, significant relationship between HBsAg positivity and mother's history of surgery, jaundice, blood transfusion and jaundice in the husbands was seen in a study carried out in Khartoum [13].

A study carried out in Al Fashir found a significant association between HBV infection and some factors included residence, income, occupation, bloodletting, and ear piercing [17]. These variations may be attributed to the sensitivity of diagnostic tests used or cultural and behavioral differences. 
TABLE 2: $P$-value and odds ratio analysis of the possible risk factors for HBsAg among the study population.

\begin{tabular}{|l|c|c|c|c|c|c|}
\hline & $\begin{array}{c}\text { No. } \\
\text { studied }\end{array}$ & No. +ve & (\%) & *P-value & $\begin{array}{c}\text { Odds } \\
\text { ratio }\end{array}$ & $\begin{array}{c}\text { 95\% Confidence } \\
\text { interval }\end{array}$ \\
\hline Blood transfusion & 7 & 0 & 0.00 & 0.41 & 0.69 & $0.3-1.86$ \\
\hline Surgical procedure & 11 & 1 & 9.09 & 0.94 & 0.78 & $0.7-2.5$ \\
\hline Dental procedure & 10 & 1 & 10.00 & 0.86 & 0.82 & $0.6-1.9$ \\
\hline Tattooing & 20 & 0 & 0.00 & 0.15 & 0.98 & $0.5-2.3$ \\
\hline Cupping therapy & 23 & 1 & 4.35 & 0.44 & 0.79 & $0.3-1.84$ \\
\hline Unsafe injection & 7 & 0 & 0.00 & 0.41 & 0.96 & $0.6-1.7$ \\
\hline Caesarean section & 9 & 0 & 0.00 & 0.35 & 1.0 & $0.5-1.88$ \\
\hline Ear piercing & 159 & 12 & 7.55 & 0.10 & 0.99 & $0.6-2.7$ \\
\hline Liver problem or jaundice & 50 & 5 & 10.00 & 0.65 & 0.93 & $0.3-1.7$ \\
\hline Husband's jaundice & 27 & 4 & 14.81 & 0.20 & 0.66 & $0.6-2.1$ \\
\hline Abortion or miscarriage & 45 & 5 & 11.11 & 0.46 & 0.70 & $0.4-1.2$ \\
\hline Female circumcision & 149 & 13 & 8.72 & 0.74 & 0.87 & $0.5-2.4$ \\
\hline${ }^{*} P$-value < 0.05 is considered significant. & & & & &
\end{tabular}

\subsection{Limitations of the study}

Regarding the high prevalence of HBsAg in the current study; the duration of the study is short, based only on the detection of HBsAg by rapid test, and the population investigated consisted only of women who were able to access antenatal care, thus the prevalence reported here may have underestimated the true prevalence among pregnant women in the larger community.

\section{Conclusion}

The study concluded that HBV infection is prevalent among pregnant women in the Um Dafog area and classifies it as high zone of endemicity according to the WHO, so further studies covering larger community using robust diagnostic techniques are highly recommended to support these findings. Furthermore, all pregnant women should be screened for HBV, treated if necessary to reduce their viral loads, and their children being should be vaccinated at birth with the single-dose hepatitis B vaccine to break the cycle of mother-to-child transmission.

\section{Acknowledgements}

The authors are grateful to the participants for their participation and co-operation. The authors are indebted to the laboratory staff of the Um Dafog clinic for their assistance 
during data collection and operating procedures for the laboratory tests. Provision of some laboratory materials by the Ministry of Health, South Darfur State, is acknowledged.

\section{References}

[1] WHO. (2017). Global Hepatitis Report. Geneva, Switzerland: WHO.

[2] CDC (Center for Disease Control and prevention). (2013) Hepatitis B and Sexual Health. Publication No. 21-1115. Atlanta, USA: CDC.

[3] Komatsu, H., Inui, A., and Fujisawa, T. (2016). The role of body fluids in the horizontal transmission of hepatitis B virus via household/close contact. European Medical Journal, vol. 1, no. 1, pp. 68-75.

[4] World Health Organization. (2015). Hepatitis B Fact sheet No. 204. Geneva. Retrieved from: http://www.who.int/mediacentre/factsheets/fs204/en/

[5] Yohanes, T., Zerdo, Z., and Chufamo, N. (2016). Seroprevalence and predictors of hepatitis $B$ virus infection among pregnant women attending routine antenatal care in Arba Minch Hospital, South Ethiopia. Hepatitis Research and Treatment, Article ID 9290163. doi: org/10.1155/2016/9290163.

[6] Gasim, G., Murad, I., and Adam, I. Hepatitis B and C virus infections among pregnant women in Arab and African countries. Journal of Infection in Developing Countries 2013, vol. 7, no. 8, pp. 566-578. doi: 10.3855/jidc.3243.

[7] Fessehaye, N., Berhane, A., Ahmed, H., et al. (2018). Prevalence of hepatitis B virus infection and associated seromarkers among pregnant women in Eritrea. Journal of Human Virology \& Retrovirology, vol. 6, no. 1, pp. 30-38. doi: 10.15406/jhvrv.2018.06.00191.

[8] Umare, A., Seyoum, B., Gobena, T., et al. (2016). Hepatitis B virus infections and associated factors among pregnant women attending antenatal care clinic at Deder Hospital, Eastern Ethiopia. PLOS ONE, vol. 11, no. 11, p. e0166936.

[9] Bayo, P., Ochola, E., Oleo, C., et al. (2014). High prevalence of hepatitis B virus infection among pregnant women attending antenatal care: a cross-sectional study in two hospitals in northern Uganda. BMJ, vol. 4, no. 11. doi: 10.1136/bmjopen-2014005889.

[10] Komas, N. P., Vickos, U., Hübschen, J. M., et al. (2013). Cross-sectional study of hepatitis $\mathrm{B}$ virus infection in rural communities, Central African Republic. BMC Infectious Diseases, vol. 13, no. 1, p. 286. Retrieved from: http://doi.org/10.1186/14712334-13-286 
[11] Anthony, L., Zipporah, N., Jared, O., et al. (2017). Sero-prevalence for hepatitis $B$ virus among pregnant women attending antenatal clinic in Juba Teaching Hospital, Republic of South Sudan. Pan African Medical Journal, vol. 26, p. 72. doi: 10.11604/pamj.2017.26.72.11410

[12] Abioye, J. O., Rotgak, E., Adebola, M. O. (2017). Prevalence of hepatitis B surface antigen ( $\mathrm{HBsAg})$ among pregnant women attending antenatal in Nasarawa State, Nigeria. International Journal of Innovative Science, Engineering \& Technology, vol. 4, no. 11, pp. 181-191.

[13] Abuelgasim, M. H. and Baraka, M. B. K. (2015). Prevalence of hepatitis B infection among pregnant women at Khartoum Teaching Hospital, Sudan. Journal of US China Medical Science, vol. 12, pp. 58-63.

[14] Mudawi, H. M. (2008). Epidemiology of viral hepatitis in Sudan. Clinical and Experimental Gastroenterology, vol. 1, pp. 9-13.

[15] Elsheikh, R. M., Daak, A. A., Elsheikh, M. A., et al. (2007). Hepatitis B virus and hepatitis C virus in pregnant Sudanese women. Virology Journal, vol. 4, p. 104.

[16] Osman, A. M., Mirghani, O. A., Gasim, G. I., et al. (2014). Hepatitis B virus, hepatitis $C$ virus and human immunodeficiency virus infections among pregnant women in Central Sudan. Sudan Journal of Medical Sciences, vol. 9, no. 2, pp. 91-96.

[17] El Gasim, R. A., Eltayeb, N., and El Khidir, I. (2019). Hepatitis B virus infection in pregnant women, in Al Fashir Town, North Darfur State, Sudan. Open Journal of Medical Microbiology, vol. 9, pp. 28-36.

[18] Abou, M. A., Eltahir, Y. M., and Ali, A. S. (2009). Seroprevalence of hepatitis B virus and hepatitis C virus among blood donors in Nyala, South Darfur, Sudan. Virology Journal, vol. 6, p. 146. Retrieved from: https://doi.org/10.1186/1743-422X-6-146

[19] Komas, N. P., Ghosh, S., Abdou-Chekaraou, M., et al. (2018). Hepatitis B and hepatitis $D$ virus infections in the Central African Republic, twenty-five years after a fulminant hepatitis outbreak, indicate continuing spread in asymptomatic young adults. PLOS Neglected Tropical Diseases, vol. 12, no. 4. doi: 10.1371/journal.pntd.0006377. 